\title{
EXPERIMENTAL STUDY ON THE OVERTOPPING BEHAVIOUR OF STEEP SLOPES - TRANSITION BETWEEN MILD SLOPES AND VERTICAL WALLS
}

\author{
Lander Victor ${ }^{1}$ and Peter Troch ${ }^{2}$
}

\begin{abstract}
Extensive knowledge is available on the overtopping behaviour of traditional smooth impermeable sea defence structures, such as mildly sloping dikes and vertical walls, both typically featuring a high crest freeboard to reduce wave overtopping. A particular design application emerges in the development of wave energy converters of the overtopping type, where maximisation of wave overtopping is required, i.e. smooth impermeable steep sloping structures with low crest freeboards subjected to non-breaking waves. To date, only relatively limited knowledge is available on the overtopping behaviour of those structures. In this study, the average overtopping rate obtained from new experiments has been analysed and compared with existing prediction methods. This study contributes to a better knowledge on the overtopping behaviour of the steep low-crested structures, which is positioned in between that of mildly sloping dikes and vertical walls on the one hand, and in between that of structures with zero crest freeboards and relatively large crest freeboards on the other hand. The existing prediction methods seem unable to predict the significant effects of the slope angle and small relative crest freeboards on the average overtopping rate accurately. Therefore, a new set of prediction formulae is proposed based on the new experiments combined with existing data from literature. These formulae include wave overtopping at vertical walls subjected to non-impacting waves and at structures with zero crest freeboard.
\end{abstract}

Keywords: wave overtopping, steep slope, low crest freeboard, non-breaking waves

\section{INTRODUCTION}

Traditionally, research on wave overtopping focuses on sea defence structures, which are designed to minimize the amount of water overtopping their crests. Typical examples of sea defence structures are rubble mound breakwaters, mildly sloping dikes and vertical walls, which feature relatively high crest freeboards. Extensive knowledge is available on the overtopping behaviour of these structures. An overview of the state-of-the art knowledge (acquired before 2007) is given in the EurOtop Manual (EurOtop 2007), which replaces and extends the manuals of Besley (1999), TAW (2002) and EAK (2002).

A different type of structure emerges in the development of wave energy converters based on wave overtopping (OWECs) which are planned to be installed in sea defence structures (Margheritini et al. 2009). The design of OWECs requires an inverse thinking compared to traditional sea defence structures, since wave overtopping needs to be maximized. Correspondingly, OWECs typically feature a low crest freeboard and a smooth impermeable uniform slope. Furthermore, their slopes are rather steep to avoid energy loss due to wave breaking on the slopes. The basic geometry of an OWEC, installed in a sea defence structure, thus consists of a smooth impermeable steep uniform slope extending to the seabed with a low crest freeboard. This geometry is referred to as a steep low-crested structure in the present paper. In the past, concepts of OWECs with rather complex geometries have been studied (Kofoed and Burcharth 2002; Margheritini et al. 2009). Further research on the basic geometry is required to gain insight in the relationship between the overtopping behaviour, wave characteristics and the OWEC geometry. Hence, this contributes to an improvement of the performance of (more complex) OWECs installed in sea defence structures.

This paper studies steep low-crested structures with wide ranges of application of the slope angle $\alpha$ [rad] and of the relative crest freeboard $R_{c} / H_{m 0}[-]$ (Table 1). $R_{c}[\mathrm{~m}]$ is the crest freeboard, i.e. the vertical distance between the crest of a structure and the still water level. $H_{m 0}[\mathrm{~m}]$ is the spectral wave height of the incident waves at the toe of the structure. The lower and upper limits shown in Table 1 are explained below.

Since gentle slopes have roughly $\cot \alpha \geq 2.0$ (EurOtop 2007), steep slopes correspond to values of $\cot \alpha$ smaller than 2.0. The lower limit of $\cot \alpha$ in Table 1 corresponds to vertical walls, which constitute the asymptotic geometrical configuration for very steep slopes. The upper limit of the

\footnotetext{
${ }^{1}$ Department of Civil Engineering, Ghent University, Technologiepark 904, B-9052 Zwijnaarde, Belgium, Email: lander.victor@ugent.be, Tel: +32 926454 89, Fax: +32 92645837

${ }^{2}$ Department of Civil Engineering, Ghent University, Technologiepark 904, B-9052 Zwijnaarde, Belgium, Email: peter.troch@ugent.be, Tel: +32 926454 94, Fax: +32 92645837
} 
relative crest freeboard $R_{c} / H_{m 0}$ is based on the upper limit of $R_{c} / H_{m 0}$ for low-crested vertical walls, which is approximately 1.5 (EurOtop 2007). The lower limit corresponds to structures with a zero crest freeboard, which constitute the asymptotic configuration for very low crest freeboards.

\begin{tabular}{|c|c|c|c|c|}
\hline Minimum & & Parameter & & Maximum \\
\hline 0.0 & $<$ & $\cot \alpha[-]$ & $<$ & 2.0 \\
\hline 0.0 & $<$ & $R_{c} / H_{m o}[-]$ & $<$ & 2.0 \\
\hline 2.0 & $<$ & $\xi_{m-1,0}[-]$ & & - \\
\hline 2.0 & $<$ & $h / H_{m o}[-]$ & & - \\
\hline
\end{tabular}

Since wave breaking means energy loss for OWECs, the structures studied in this paper are considered to undergo normal incident, non-breaking (surging) waves. The transition between breaking and non-breaking waves on a slope occurs approximately at a breaker parameter $\xi_{m-1,0}=\tan \alpha / \sqrt{s_{m-1,0}}=$ 2.0 [-] (EurOtop 2007) with non-breaking waves appearing for $\xi_{m-1,0}>2.0$. The wave steepness $s_{m-1,0}[-$

] is defined as the deep water wave steepness $s_{m-1,0}=2 \pi H_{m 0} / g T_{m-1,0}^{2}[-]$. Here, $g\left[\mathrm{~m} / \mathrm{s}^{2}\right]$ is the acceleration due to gravity and $T_{m-1,0}=m_{-1} / m_{0}$ [s] is the spectral incident wave period at the toe of the structure ( $m_{-1}$ is the first negative moment of the spectrum, $m_{0}$ is the zeroth moment of the spectrum). It is important to note that the relatively large values of $\xi_{m-1,0}$ are assumed to be caused by the steep slopes, not by small values of the wave steepness related to broken waves. Accordingly, the present paper only deals with impermeable slopes situated in relatively deep water, with a relative toe depth $h_{t} / H_{m 0}[-]$ larger than 2.0, where $h_{t}[\mathrm{~m}]$ is the water depth at the toe of the structure.

Based on the restrictions formulated above, the governing parameters for the average overtopping rate $q\left[\mathrm{~m}^{3} / \mathrm{s} / \mathrm{m}\right]$ of steep low-crested structures are the incident wave height $H_{m 0}$ and wave period $T_{m-1,0}$ at the toe of the structure, the slope angle $\alpha$ and the crest freeboard $R_{c}$ (Fig. 1).

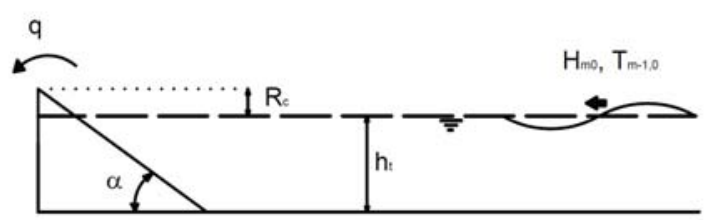

Figure 1. Definition sketch of governing parameters affecting the average overtopping rate of steep lowcrested structures.

The present paper mainly studies the relationship between these parameters for steep low-crested structures. Since literature primarily focuses on traditional sea defence structures, relatively little is known on the overtopping behaviour of steep low-crested structures. The present paper contributes to the understanding of that behaviour by comparing the average overtopping rate predicted from literature with recently achieved experimental test results.

First, a literature review is provided, giving an overview of traditional prediction models that are able to provide information on the overtopping behaviour of steep low-crested structures for the ranges of application given in Table 1. The second section describes the experimental test set-up used to obtain the recently achieved test results. Subsequently, the results of the comparison between the predicted and measured average overtopping rate are presented and discussed. In particular, the independent effects of the slope angle $\alpha$, relative crest freeboard $R_{c} / H_{m 0}$ and the wave steepness $s_{m-1,0}$ on the average overtopping rate $q$ of steep low-crested structures are investigated. Finally, a new set of prediction formulae for the average overtopping rate is derived based on both the recently achieved and existing experimental test results. 


\section{OVERVIEW OF EXISTING PREDICTION MODELS OF OVERTOPPING BEHAVIOUR OF STEEP LOW-CRESTED STRUCTURES}

To date, the number of test results on the overtopping behaviour of steep low-crested structures is rather limited. Among the more than 10.000 test results of wave overtopping tests with vast ranges of geometries and wave characteristics, which have been collected during the CLASH project (De Rouck and Geeraerts 2005) and gathered in the CLASH database (Van der Meer et al. 2005), only 182 test results correspond to steep low-crested structures which fulfil the ranges of application in Table 1. The minimum value of $R_{c} / H_{m 0}$ for those test results only equals 0.5 , while the corresponding resolution for $\cot \alpha$ is also rather low. As a consequence, the overtopping behaviour of steep low-crested structures cannot be predicted sufficiently accurate for use in wave energy projects based on these test results.

The slopes of steep low-crested structures are situated in between those of mildly sloping dikes and vertical walls (Table 1). Furthermore, the crest freeboards are positioned in between those of structures with zero crest freeboards and structures with relatively high crest freeboards. Consequently, the average overtopping rate is expected to be positioned in between the average overtopping rate of these neighbouring (from a geometrical point of view) structures. An interpolation between the predicted average overtopping rate of those structures is thus required. This can be achieved by (1) directly interpolating between the predicted average overtopping rate of each of the neighbouring structures, or (2) predicting the average overtopping rate using prediction models that cover all neighbouring structures.

The first approach is based on predictions by empirical formulae (with wide ranges of relative crest freeboards) for mildly sloping dikes and vertical walls, and on available test results for zero crest freeboards. The major part of these is also mentioned in the EurOtop Manual (EurOtop 2007).

The average overtopping rate of mildly sloping dikes subjected to non-breaking waves is commonly predicted using Eq. (1) (EurOtop 2007).

$$
\frac{q}{\sqrt{g H_{m 0}^{3}}}=0.20 \exp \left[(-2.6) \frac{R_{c}}{H_{m 0}}\right]
$$

The corresponding ranges of application for the slope angle and relative crest freeboard are: $1.0<\cot \alpha<4.0$ and $0.5<R_{c} / H_{m 0}<3.5$. The reliability of Eq. (1) is expressed by considering the coefficient -2.6 as a normally distributed stochastic variable with mean -2.6 and standard deviation $\sigma=0.35$.

Owen (1980) also derived a prediction formula for the average overtopping rate at mildly sloping dikes. However, since this formula tends to overestimate the average overtopping rate for mildly sloping dikes with non-breaking waves (EurOtop 2007), its predictions are not considered in the present paper.

The asymptotic overtopping behaviour for very steep low-crested structures, fulfilling the ranges of application in Table 1, is determined by the overtopping behaviour at vertical walls, subjected to non-impulsive wave attack. Franco et al. (1994) derived an equation (Eq.2) based on 2D experimental tests on vertical walls in relatively deep water $\left(h_{t} / H_{m 0}>3.0\right)$ with relative crest freeboards $0.8<R_{c} / H_{m 0}<3.0$.

$$
\frac{q}{\sqrt{g H_{m 0}^{3}}}=0.2 \exp \left[(-4.3) \frac{R_{c}}{H_{m 0}}\right]
$$

The standard deviation for the coefficient -4.3 in Eq. (2) equals $\sigma=0.3$. A second equation (EurOtop 2007), given in Eq. (3), has a wider range of application for the relative crest freeboard, $0.1<R_{c} / H_{m 0}<3.5$, while the $90 \%$ prediction interval is also wider: the coefficient -2.6 corresponds to a standard deviation $\sigma=0.8$.

$$
\frac{q}{\sqrt{g H_{m 0}^{3}}}=0.04 \exp \left[(-2.6) \frac{R_{c}}{H_{m 0}}\right]
$$


Note that the equations above are not valid for very small crest freeboards. For structures with a zero crest freeboard, test results with slopes $\cot \alpha=0.0$ and $\cot \alpha=1.5$ (Smid et al. 2001) and with $3.0 \leq \cot \alpha \leq 6.0$ (Schüttrumpf 2001) are available. An empirical formula based on the test results of Schüttrumpf (2001) is provided by EurOtop (2007); its expression is given in Eq. (4).

$$
\frac{q}{\sqrt{g H_{m 0}^{3}}}=\left(0.136-\frac{0.226}{\xi_{m-1,0}^{3}}\right)
$$

It should be noted that the test results of Smid et al. (2001) have a reliability factor of 4 (unreliable) in the CLASH database. However, these are the only available tests on steep slopes and vertical walls with zero crest freeboards and they are also mentioned in the EurOtop Manual. The test results by Smid et al. (2001) are used in the present paper to predict the average overtopping rate at steep slopes and vertical walls with zero crest freeboards.

Concerning the second approach, two prediction models are applied in the present paper. Both models are based on the CLASH database and cover all neighbouring structures. The first model (Goda 2009) consists of an empirical prediction formula, which has been derived through simple regression analysis of a subset of data of the CLASH database containing both mildly sloping dikes and vertical walls. The relative toe depth $h_{t} / H_{m 0}$ of this subset ranges between 0.0 and 23.0. When $h_{t} / H_{m 0}$ is larger than 2.0 (as assumed in Table 1), the effect of the relative toe depth on the average overtopping rate is negligible (Goda 2009), hence simplifying the empirical prediction formula of Goda (2009). The corresponding formula $\left(h_{t} / H_{m 0}>2.0\right)$ is given in Eq. (5).

$$
\begin{gathered}
\frac{q}{\sqrt{g H_{m 0}^{3}}}=\exp \left[-\left(A_{0}+B_{0} \frac{R_{c}}{H_{m 0}}\right)\right] \\
A_{0}=3.4-0.734 \cot \alpha+0.239(\cot \alpha)^{2}-0.0162(\cot \alpha)^{3} \\
B_{0}=2.3-0.5 \cot \alpha+0.15(\cot \alpha)^{2}-0.011(\cot \alpha)^{3}
\end{gathered}
$$

The ranges of application of Eq. (5) for the slope angle and relative crest freeboard are: $0.0 \leq \cot \alpha \leq 7.0$ and $0.0 \leq R_{c} / H_{m 0} \leq 5.7$. The limits for the $90 \%$ prediction interval of Eq. (5) are determined by $\left[\left(q / \sqrt{g H_{m 0}^{3}}\right)_{E q .(5)}\right]^{7 / 5}$ (lower limit) and by $\left[\left(q / \sqrt{g H_{m 0}^{3}}\right)_{E q .(5)}\right]^{2 / 3}$ (upper limit).

The coefficients $A_{0}[-]$ (Eq. 5b) and $B_{0}[-]$ (Eq. 5c) depend on the structure slope cot $\alpha$ and have been determined through simple regression of CLASH test results for different values of cot $\alpha$ (Goda 2009). Note that Eq. (5) approximately reduces to Eq. (3) for $\cot \alpha=0.0$. Furthermore, compared to Eq. (1), Eq. (5) takes into account the effect of the slope angle for mildly sloping dikes.

The second prediction model which covers all neighbouring structures is the DHNN (Delft Hydraulics Neural Network) tool (EurOtop 2007; Van Gent et al. 2007). This tool has been developed by Delft Hydraulics (The Netherlands) and is trained using the major part of all test results of the CLASH database. Although the number of test results on steep low-crested slopes in the CLASH database that fulfil the requirements from Table 1 is limited, the DHNN tool is able to predict their average overtopping rate through interpolation between test results for mildly sloping dikes and vertical walls. The ranges of application of the DHNN tool for the slope angle and relative crest freeboard are: $0.0 \leq \cot \alpha \leq 7.0$ and $0.0 \leq R_{c} / H_{m 0} \leq 6.4$. The reliability of the DHNN tool is given as part of the output of the neural network.

An important drawback for using these two models, Eq. (5) and the DHNN tool, is the wide variety of waves and structures they are based upon. The models consider both breaking and nonbreaking waves, and both impacting and non-impacting wave attack. Accordingly, their 90\% prediction interval is rather wide compared to the more restricted prediction models, i.e. for vertical walls (Eq. 2 and Eq. 3) or for mildly sloping dikes (Eq. 1). 
Deviating from the interpolation approaches discussed above, Kofoed (2002) presents an empirical prediction formula (Eq. 6) that extends the ranges of application of Eq. (1) to steeper slopes and to smaller relative crest freeboards.

$$
\frac{q}{\sqrt{g H_{m 0}^{3}}}=\lambda_{d r} \lambda_{\alpha} \lambda_{s} 0.20 \exp \left[(-2.60) \frac{R_{c}}{H_{m 0}}\right]
$$

The formula is based on experimental tests with scale models of fixed OWECs characterized by a single uniform slope and mainly featuring a limited draft (slope not extending to the seabed). The corresponding ranges are: $0.58<\cot \alpha<2.75$ and $0.15<R_{c} / H_{m 0}<2.0$. Basically, Eq. (6a) is based on Eq. (1), where a number of correction coefficients have been added to align the formula with the experimental test results of Kofoed (2002).

The effect of the limited draft on the average overtopping rate is taken into account by the coefficient $\lambda_{d r}$ [-], which equals 1.0 when the slope extends to the seabed. The dimensionless coefficient $\lambda_{\alpha}[-]$, defined in Eq. (6b), expresses an observed decrease in average overtopping rate for characteristic slope angles $\alpha_{\circ}$ deviating from $\cot \alpha=1.73\left(30^{\circ}\right)$, while the coefficient $\lambda_{s}[-]$ compensates for an observed overestimation of the average overtopping rate by Eq. (1) for relative crest freeboards $R_{c} / H_{m 0}<0.75$ (Eq. 6c).

$$
\begin{gathered}
\lambda_{\alpha}=\left[\cos \left(\alpha_{\circ}-30^{\circ}\right)\right]^{3} \\
\lambda_{s}=\left\{\begin{array}{ll}
0.40 \sin \left(\frac{2}{3} \pi \frac{R_{c}}{H_{m 0}}\right)+0.60 & \frac{R_{c}}{H_{m 0}}<0.75 \\
1.0 & \frac{R_{c}}{H_{m 0}} \geq 0.75
\end{array}\right\}
\end{gathered}
$$

$\lambda_{s}$ has been calibrated using test results of Schüttrumpf (2001) for structures with a zero crest

\begin{tabular}{|c|c|c|c|}
\hline Eq. Nr. & Reference & $\cot \alpha[-]$ & $R_{c} / H_{m o}[-]$ \\
\hline (1) & EurOtop (2007) & $1.0-4.0$ & $0.5-3.5$ \\
\hline (2) & Franco et al. (1994) & 0.0 & $0.8-3.0$ \\
\hline (3) & EurOtop (2007) & 0.0 & $0.1-3.5$ \\
\hline (4) & Schüttrumpf (2001) & $3.0-6.0$ & 0.0 \\
\hline (5) & Goda (2009) & $0.0-7.0$ & $0.0-5.7$ \\
\hline (6) & Kofoed (2002) & $0.58-2.75$ & $0.15-2.0$ \\
\hline
\end{tabular}
freeboard and with $3.0 \leq \cot \alpha \leq 6.0$.

A summary of the empirical prediction formulae mentioned above is given in Table 2.

\section{TEST SET-UP OF NEW EXPERIMENTS}

The new experiments, referred to as the UG10 test series, have been carried out in a wave flume $30 \mathrm{~m}$ long, $1 \mathrm{~m}$ wide and $1.2 \mathrm{~m}$ high - at the Department of Civil Engineering at Ghent University (Belgium) (Fig.2). The tested structures feature uniform smooth impermeable steep slopes extending to the seabed and low crest freeboards. The average overtopping rate is measured using the weigh cell technique (e.g. Franco et al. 1994; Schüttrumpf 2001). For a large average overtopping rate, this technique requires water to be pumped from the reservoir on the weigh cell to the wave flume. The structures are positioned on top of a hollow bottom, enabling the transport of pumped water below the structure, thus not affecting the incoming waves. The bottom features a rather short transition slope of $1: 20$, starting at a distance of $10 \mathrm{~m}$ from the wave paddle, followed by a horizontal part up to a distance of $24 \mathrm{~m}$ from the paddle. This horizontal part reduces the depth of the flume by $0.27 \mathrm{~m}$. The crest of the structures has a fixed position, at $0.57 \mathrm{~m}$ above the horizontal part of the bottom, i.e. the "point of 
rotation" for the slopes (Fig.2). More details on the test set-up are presented in (Victor and Troch 2010).

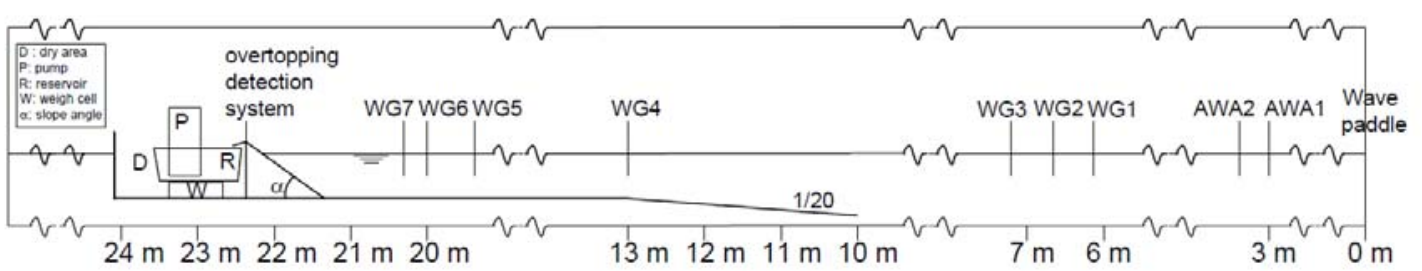

Figure 2. Cross-section of the test set-up of the new experiments along the length of the wave flume (WG = wave gauge; AWA = wave gauge used for active wave absorption).

In order to study the independent effects of slope angle, crest freeboard and wave steepness on the average overtopping rate $q$, broad ranges of those parameters have been used during the experiments.

Nine slope angles are used, from steep to mild, varying between $\cot \alpha=0.36$ and $\cot \alpha=2.75$. Each of these slope angles is combined with three crest freeboards. A varying crest freeboard is achieved by varying the water depth on the horizontal part of the bottom between $0.50 \mathrm{~m}, 0.525 \mathrm{~m}$ and $0.55 \mathrm{~m}$. The corresponding values for the crest freeboard $R_{c}$ are $0.07 \mathrm{~m}, 0.045 \mathrm{~m}$ and $0.02 \mathrm{~m}$. An overview of the applied geometrical parameters is given in Table 2. In order to validate the UG10 dataset against existing knowledge for the traditional sea defence structures, the range of application of $\cot \alpha$ in Table 1 has been extended to larger values (as shown in Table 3).

\begin{tabular}{|c|c|}
\hline Parameter & Values \\
\hline $\cot \alpha[-]$ & $0.36,0.58,0.84,1.00,1.19,1.43,1.73,2.14,2.75$ \\
\hline$R_{c}[\mathrm{~m}]$ & $0.020,0.045,0.070$ \\
\hline
\end{tabular}

The different geometries have been subjected to irregular waves, generated using a piston-type wave paddle. A summary of the combinations of spectral significant wave height $H_{m 0}$ and peak period $T_{p}$ during the UG10 test series is shown in Table 4. A parameterized JONSWAP spectrum with peak enhancement factor 3.3 is applied. At least 1000 waves have been generated for each experimental test, in order to obtain values of the average overtopping rate that are statistically independent of the number of waves of the test. The methodology described by Mansard and Funke (1980), applying the signals of three wave gauges, has been used to determine the incident wave characteristics at the toe of the structure.

\begin{tabular}{|c|c|c|c|c|c|}
\hline \multirow[t]{2}{*}{$H_{m o}[\mathrm{~m}]$} & \multicolumn{5}{|c|}{$T_{p}[\mathrm{~s}]$} \\
\hline & 1.0 & 1.3 & 1.5 & 1.8 & 2.0 \\
\hline 0.020 & $X$ & & & & \\
\hline 0.033 & $X$ & $X$ & & & \\
\hline 0.067 & $x$ & $x$ & $X$ & & \\
\hline 0.10 & & $x$ & $x$ & $x$ & \\
\hline 0.13 & & & $x$ & $x$ & $X$ \\
\hline 0.17 & & & & $x$ & $x$ \\
\hline 0.19 & & & & & $x$ \\
\hline
\end{tabular}

Although relatively small wave heights have been used in a number of tests, the influence of scale effects is expected to be marginal since the tested structures feature smooth impermeable slopes. This is confirmed by previous research on structures with identical features (Kofoed 2002).

In total, 349 irregular wave tests have been carried out. The test matrix allows to study the independent effects of slope angle, crest freeboard, and wave steepness on the overtopping behaviour of steep low-crested structures in detail. The results are gathered in a dataset, referred to as the UG10 
dataset. The corresponding ranges of application for the relative crest freeboard $R_{c} / H_{m 0}$ and wave steepness $s_{m-1,0}$ are:

$$
\begin{gathered}
0.11<\frac{R_{c}}{H_{m 0}}<1.70 \\
0.015<s_{m-1,0}<0.05
\end{gathered}
$$

Furthermore, the relative water depth $h_{t} / H_{m 0}$ is larger than 2.5 for all tests. The broad ranges of application for the slope angle and wave steepness result in a broad range of application for the breaker parameter $\xi_{m-1,0}$ (Eq. 9). All tests correspond to non-breaking waves, since $\xi_{m-1,0}>2.0$. Note that the ranges of application of the UG10 data fit the limits prescribed in Table 1.

$$
2.0<\xi_{m-1,0}<21.5
$$

The test conditions of the UG10 test series are similar to the conditions of the tests carried out by Kofoed (2002). However, due to the fact that the structures tested in the present paper are part of a sea defence structure, all slopes extend to the bottom of the seabed, in contrast to the limited draft used by Kofoed (2002).

\section{EFFECT OF SLOPE ANGLE ON OVERTOPPING RATE OF STEEP LOW-CRESTED STRUCTURES}

The independent effect of the slope angle $\alpha$ on the average overtopping rate of steep low-crested structures is studied by analyzing test results with identical values for crest freeboard $R_{c}$, peak wave period $T_{p}$ and wave height $H_{m 0}$, and by comparing these test results with their predicted values.

The dimensionless average overtopping rate $q / \sqrt{g H_{m 0}^{3}}$ [-] (logarithmic scale) for test results with $R_{c}=0.045 \mathrm{~m}, H_{m 0}=0.067 \mathrm{~m}$ and $T_{p}=1.53 \mathrm{~s}$ (all dimensions in model scale) is shown as a function of the cotangent of the slope angle $\cot \alpha$ (linear scale) in a log-linear graph in Fig. 3a. The corresponding relative crest freeboard $R_{c} / H_{m 0}$ equals 0.67 . The horizontal axis covers the range $0.0 \leq \cot \alpha \leq 4.0$.

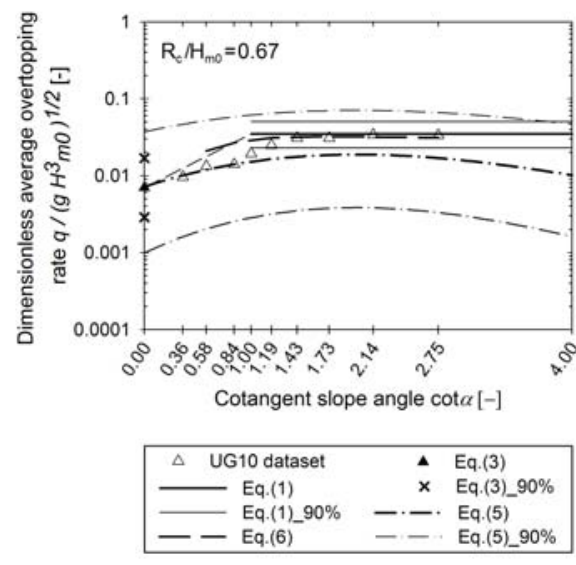

(a)

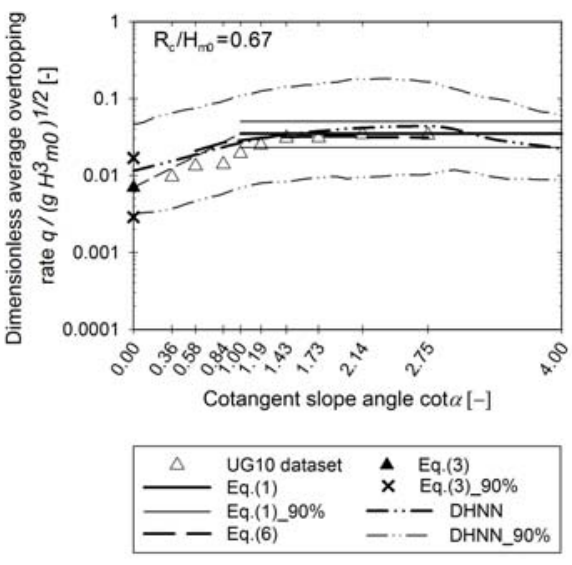

(b)

Figure 3. Graph of dimensionless average overtopping rate $q / \sqrt{g H_{m 0}^{3}}$ as a function of the slope angle $\cot \alpha$, for $R_{c} / H_{m 0}=\mathbf{0 . 6 7}$.

Furthermore, the dimensionless average overtopping rate predicted by Eq. (1), Eq. (3), Eq. (5) and Eq. (6) for the same set of $R_{c}, H_{m 0}$ and $T_{p}$ has been calculated within their ranges of application for $\cot \alpha$ (Fig. 3a). The $90 \%$ prediction intervals of Eq. (1), Eq. (3) and Eq. (5) are also shown. Fig. 3b is a similar figure, where the predictions by Eq. (5) have been replaced by the predictions of the DHNN tool. 
A rough prediction of the dimensionless average overtopping rate of steep low-crested structures is achieved by interpolating between the predicted value of Eq. (1) (solid line) for $\cot \alpha=1.0$ and the prediction of Eq. (3) for $\cot \alpha=0.0$ (triangle on vertical axis). The corresponding short-dashed line indicates that a decrease in average overtopping rate occurs from mildly sloping dikes with nonbreaking waves up to vertical walls subjected to non-impulsive wave attack. EurOtop (2007) has also drawn the same conclusion for larger relative crest freeboards $\left(R_{c} / H_{m 0}=1.5\right.$ and $\left.R_{c} / H_{m 0}=3.0\right)$ based on a similar approach.

The predictions given by Eq. (5) (dash-dot line), the DHNN tool (dash dot-dot line) and Eq. (6) (long-dashed line) are expected to be more accurate. These predictions confirm the decreasing trend in the dimensionless average overtopping rate for slopes increasing from $\cot \alpha=2.0$ to $\cot \alpha=0.0$ for Eq.(5) and the DHNN tool, or to $\cot \alpha=0.58$ for Eq. (6). However, the predicted average overtopping rate from each of these three prediction models do not agree very well in the range $0.0 \leq \cot \alpha \leq 1.0$. Although both Eq. (5) and the DHNN tool are based on the CLASH database, the differences in the corresponding predicted average overtopping rate are rather large. Furthermore, the predictions by Eq. (6) are based on structures (mainly) with a limited draft, while the test results of the CLASH database are determined for slopes extending to the seabed.

The predictions by the DHNN tool are expected to be the most accurate of these three prediction models, since this tool takes a larger number of parameters into account compared to Eq. (5) and only structures with a slope extending to the seabed are considered.

The data points of the UG10 dataset describe two trend lines (Fig. 3a and Fig. 3b): a quasihorizontal trend line for the milder slopes and a descending trend line for steep slopes with increasing slope angle, which confirms the descending trend of the predictions.

The quasi-horizontal trend line falls within the $90 \%$ prediction interval of Eq. (1). On the other hand, when the slope becomes steeper, the trend line descends towards the prediction by Eq. (3) for $\cot \alpha=0.0$, and intersects the lower boundary of the $90 \%$ prediction interval approximately at $\cot \alpha=1.1$. However, the standard deviation $\sigma=0.35$ of Eq. (1) derived by (EurOtop 2007) is based on a broad range of sea defence structures. The value of $\sigma$ is expected to decrease when only straight smooth impermeable slopes exposed to normal wave attack are considered, i.e. applicable to the type of structures considered in this paper. Accordingly, the $90 \%$ prediction interval of Eq. (1) in Fig. 3a and Fig. $3 \mathrm{~b}$ is expected to be narrower than shown in these figures. This results in a shift of the intersection point of the descending trend line and lower boundary of the $90 \%$ prediction interval towards higher values of $\cot \alpha$, assumed to be positioned at approximately $\cot \alpha=1.5$.

Since the UG10 test results with $\cot \alpha<1.5$ significantly deviate from Eq. (1), the accuracy of the three prediction models discussed above has been further analyzed. The test results with $\cot \alpha<1.5$ are positioned within the $90 \%$ prediction intervals of Eq. (5) and the DHNN tool. These intervals are rather wide, and relatively large differences occur between the test results and the average predictions. The average overtopping rate predicted by Eq. (5) is generally smaller compared to the measured average overtopping rate, while the average predictions by the DHNN tool tend to overestimate the average overtopping rate for slopes steeper than 1:1. Furthermore, different predictions are given by Eq. (5) and the DHNN tool for the asymptotic case of $\cot \alpha=0.0$ (Fig. 3). Since Eq. (5) approximately reduces to Eq. (3) for $\cot \alpha=0.0$, the corresponding prediction line intersects the vertical axis around the triangle corresponding to Eq. (3).

The decreasing trend predicted by $\lambda_{\alpha}$ in Eq. (6b) for slopes steeper than $\cot \alpha=1.73$ is not sufficient to describe the decreasing trend of the data points of the UG10 dataset. This is due to the effect of the limited draft.

Based on the discussion above, none of the considered prediction models is able to predict the average overtopping rate accurately in the zone $\cot \alpha<1.5$ for the example in Fig. 3. Similar graphs for different values of $R_{c} / H_{m 0}$ are given in Fig. 4 and Fig. 5 respectively. Fig. 4 shows test results of the UG10 dataset with $R_{c}=0.045 \mathrm{~m}, H_{m 0}=0.10 \mathrm{~m}$ and $T_{p}=1.53 \mathrm{~s}$. The corresponding relative crest freeboard $R_{c} / H_{m 0}$ equals 0.45 . The predictions by Eq. (1) are represented with dotted lines, since its range of application for $R_{c} / H_{m 0}$ is violated. The test results of the UG10 dataset are positioned significantly below the prediction line of Eq. (1). Again, the average predictions by Eq. (5) and Eq. (6) are not sufficiently accurate. However, in contrast to Fig. 3, the DHNN tool provides relatively accurate predictions for the example in Fig. 4. 


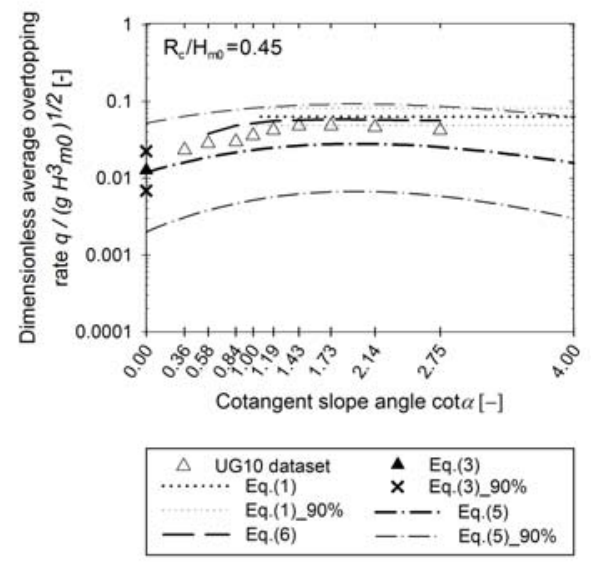

(a)

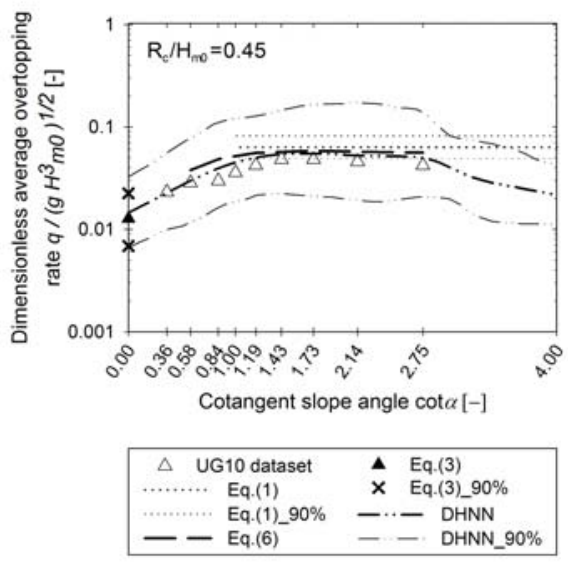

(b)

Figure 4. Graph of dimensionless average overtopping rate $q / \sqrt{g H_{m 0}^{3}}$ as a function of the slope angle $\cot \alpha$, for $R_{c} / H_{m 0}=\mathbf{0 . 4 5}$.

The data points in Fig. 5 correspond to $R_{c}=0.045 \mathrm{~m}, H_{m 0}=0.033 \mathrm{~m}$ and $T_{p}=1.28 \mathrm{~s}$, yielding a relative crest freeboard $R_{c} / H_{m 0}=1.36$. Here, also Eq. (2) is added to the log-linear graph. The interpolation between Eq. (2) and the predicted value by Eq. (1) for $\cot \alpha=1.0$ is represented by a long-short-dashed line in Fig. 5.

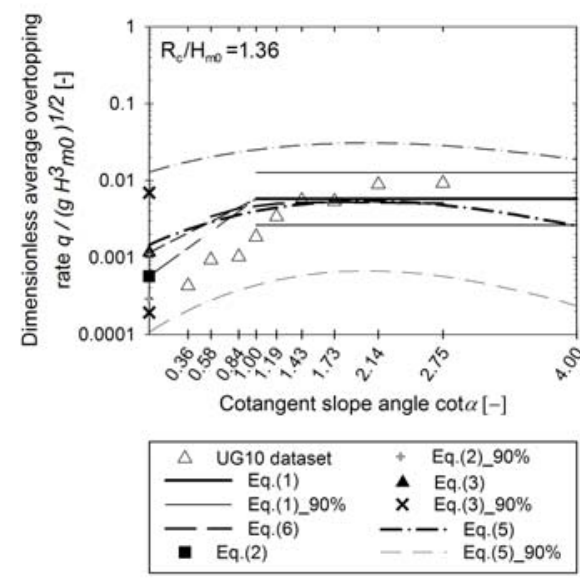

(a)

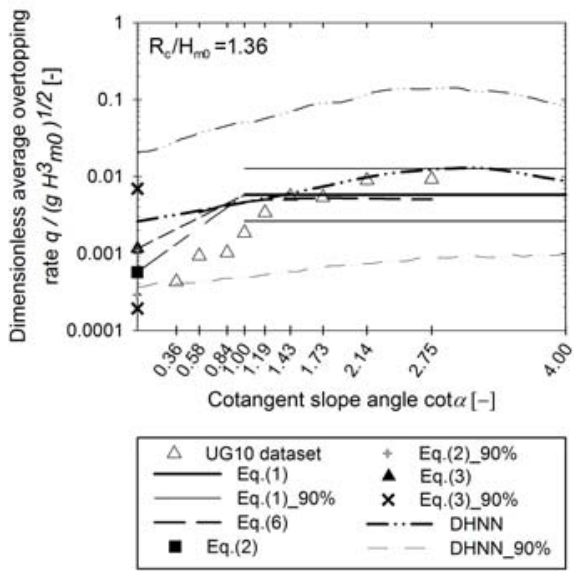

(b)

Figure 5. Graph of dimensionless average overtopping rate $q / \sqrt{g H_{m 0}^{3}}$ as a function of the slope angle $\cot \alpha$, for $R_{c} / H_{m 0}=1.36$.

The conclusions on the accuracy of the prediction models for the example in Fig. 5 are similar to those for Fig. 3. The transition point between the descending trend line and the horizontal trend line of the UG10 test results is also assumed to be positioned approximately at $\cot \alpha=1.50$.

However, the overpredictions of the measured average overtopping rate for the steepest slopes are even larger. Furthermore, the trend line followed by the test results with steeper slopes descends towards the predicted value by Eq. (2) instead of Eq. (3) for $\cot \alpha=0.0$.

It is concluded that the predictions of the UG10 test results by Eq. (5), the DHNN tool and Eq. (6) are relatively poor.

When Fig. 3 is compared to Fig. 5, the significant effect of the slope angle for steeper slopes appears to decrease as the relative crest freeboard decreases. Based on this observation, it is worthwhile to take a look at the effect of the slope angle on the average overtopping rate of structures with a zero crest freeboard (Fig. 6). As mentioned in the first section, test results (e.g. Smid et al. 2001) and prediction methods (e.g. Eq. 4) are available in literature for such a crest freeboard. 


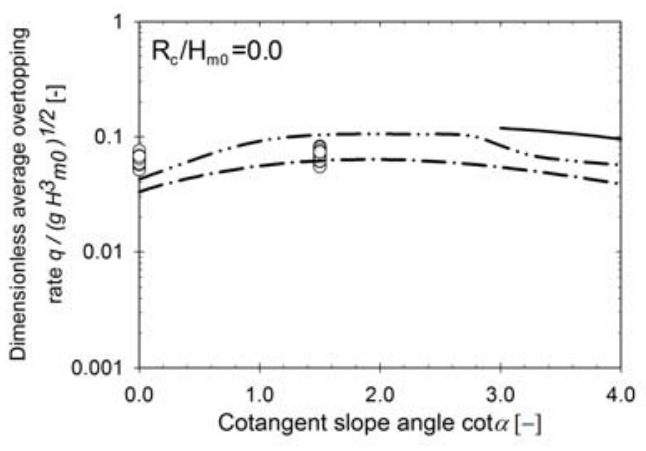

\begin{tabular}{|c|c|}
\hline - Smid et al. (2001) & -.- $\cdot$ DHNN \\
\hline
\end{tabular}

Figure 6. Graph of dimensionless average overtopping rate $q / \sqrt{g H_{m 0}^{3}}$ as a function of the slope angle $\cot \alpha$, for $R_{c} / H_{m 0}=\mathbf{0 . 0}$.

Similar to Fig. 3, Fig. 4 and Fig. 5, a decrease in the average overtopping rate is predicted by Eq. (5) and the DHNN tool for slope angles increasing from $\cot \alpha=2.0$ to $\cot \alpha=0.0$. On the other hand, the test results of Smid et al. (2001) predict an independency on the slope angle, with a constant value of $q / \sqrt{g H_{m 0}^{3}}=0.062$. This is due to the fact that the test results of Smid et al. (2001) have not been used for deriving Eq. (5), nor for training the DHNN tool. Since Eq. (4) predicts a dependency of the average overtopping rate on the slope angle for mild slopes, the existence of a constant average overtopping rate for steep slopes however is questionable.

The observations in Fig. 6 confirm the interaction between the effects of $\cot \alpha$ and $R_{c} / H_{m 0}$ on the dimensionless average overtopping rate $q / \sqrt{g H_{m 0}^{3}}$ for steep low-crested structures. The effect of $R_{c} / H_{m 0}$ on $q / \sqrt{g H_{m 0}^{3}}$ is discussed in the next section.

\section{EFFECT OF CREST FREEBOARD ON OVERTOPPING RATE OF STEEP LOW-CRESTED STRUCTURES}

The predicted effect of the relative crest freeboard on the average overtopping rate of steep lowcrested structures for $\cot \alpha=1.5$ is shown in Fig. 7. A rather rough prediction is achieved by directly interpolating between the average overtopping rate predicted for $\cot \alpha=1.5$ by Eq. (1) for $R_{c} / H_{m 0}=0.5$ and the test results of Smid et al. (2001) for a zero crest freeboard. The corresponding short-dashed line gently increases for decreasing relative crest freeboard towards the test results of Smid et al. (2001), which are situated below the extension of Eq. (1) to lower relative crest freeboards (dotted line).

This trend is confirmed by the prediction lines corresponding to Eq. (5) and to the DHNN tool for $\cot \alpha=1.5$, which predict a more gentle increase in average overtopping rate for decreasing relative crest freeboard. Both models intersect the vertical axis around the location of the test results of Smid et al. (2001). The predictions by Eq. (6) for smaller relative crest freeboards $\left(R_{c} / H_{m 0}<0.75\right)$, assuming a slope $\cot \alpha=1.73$, are also located below the prediction line of Eq. (1), due to the presence of the coefficient $\lambda_{s}$. Furthermore, test results with smooth impermeable steep slopes with $\cot \alpha=1.0$ and $\cot \alpha=2.0$ used for deriving Eq. (1) are also added to Fig. 7. Only a small number of those test results feature a relative crest freeboard $R_{c} / H_{m 0}<1.0$. The corresponding data points deviate from Eq. (1) for lower relative crest freeboards towards the data points of Smid et al. (2001), reaching the lower boundary of the $90 \%$ prediction interval of Eq. (1) at approximately $R_{c} / H_{m 0}=0.6$.

All of these arguments indicate that Eq. (1) significantly overestimates the average overtopping rate for structures with small relative crest freeboards. Accordingly, the overtopping behaviour of smooth impermeable uniform slopes is not described sufficiently accurate by a single straight line in a 
log-linear graph of the average overtopping rate as a function of the relative crest freeboard. This is similar to the case of breaking waves, where the average overtopping rate follows a curved line when plotted in a log-linear graph as a function of the relative crest freeboard (Battjes 1974).

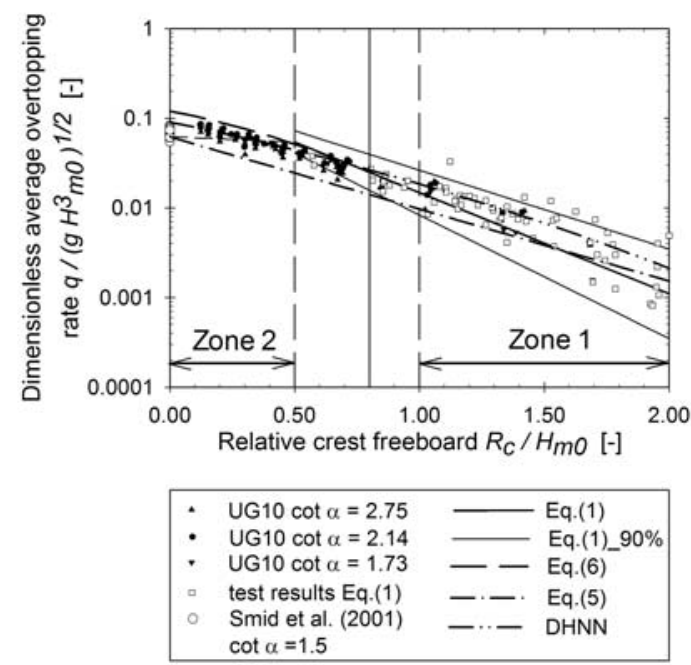

Figure 7. Graph of dimensionless average overtopping rate $q / \sqrt{g H_{m 0}^{3}}$ as a function of the relative crest freeboard $R_{c} / H_{m 0}$, for $\cot \alpha=\mathbf{1 . 5}$.

The deviating behaviour for structures with smaller relative crest freeboards subjected to nonbreaking waves is also confirmed by the test results of the UG10 dataset with $\cot \alpha>1.5$ (Fig. 7).

Three different zones of overtopping behaviour are identified for the test results of the UG10 dataset in Fig. 7: $1.0 \leq R_{c} / H_{m 0} \leq 2.0$ (zone 1), $0.0 \leq R_{c} / H_{m 0} \leq 0.5$ (zone 2) and the transition zone in between, $0.5<R_{c} / H_{m 0}<1.0$. In the first zone, all UG10 data points (black symbols) are located within the $90 \%$ prediction interval of Eq. (1). This means that the effect of $R_{c} / H_{m 0}$ on $q / \sqrt{g H_{m 0}^{3}}$ is accurately described by the exponential function of Eq. (1). In the second zone $\left(0.0 \leq R_{c} / H_{m 0} \leq 0.5\right)$ the UG10 data points significantly deviate from Eq. (1). The relationship between $q / \sqrt{g H_{m 0}^{3}}$ and $R_{c} / H_{m 0}$ appears to be linear in the log-linear graph for zone 2, suggesting that an exponential function can be fitted through the data points.

In between both zones, a transition zone occurs $\left(0.5 \leq R_{c} / H_{m 0} \leq 1.0\right)$. Since the confidence interval of Eq. (1) is expected to be narrower than shown in the figure when only considering straight, smooth impermeable slopes, the UG10 data points are expected to significantly deviate from Eq. (1) for a value of $R_{c} / H_{m 0}$ larger than 0.5 . Predictions of the average overtopping rate of steep low-crested structures using Eq. (1) are assumed to be only valid for $R_{c} / H_{m 0}>0.8$.

The factor $\lambda_{s}$ (Eq. 6) appears to be insufficient to describe the trend line of the data points of the UG10 dataset for $R_{c} / H_{m 0}<0.8$. This is due to the fact that test results of Schüttrumpf (2001) for structures featuring zero crest freeboards and milder slopes, which are positioned above the test results of Smid et al. (2001), have been used for calibration. On the other hand, the predictions by the DHNN tool are relatively accurate for the test results of the UG10 dataset with $\cot \alpha>1.5$, while the prediction line corresponding to Eq. (5) is positioned below those test results. Both predictions are also visible for $\cot \alpha>1.5$ in Fig. 3 to Fig. 5.

The dimensionless average overtopping rate $q / \sqrt{g H_{m 0}^{3}}$ (logarithmic scale) of all test results of the UG10 dataset is plotted versus the relative crest freeboard $R_{c} / H_{m 0}$ (linear scale) combined with the predictions of Eq. (1) and its $90 \%$ prediction interval (Fig. 8). The data points corresponding to tests with a slope milder than the transition point for the slope angle $(\cot \alpha=1.5)$, are marked in black. The data points with a steeper slope are marked using white symbols. The double-linear behaviour 
described above for the test results with $\cot \alpha>1.5$ is also visible for the other tested slope angles (Fig. $8)$.

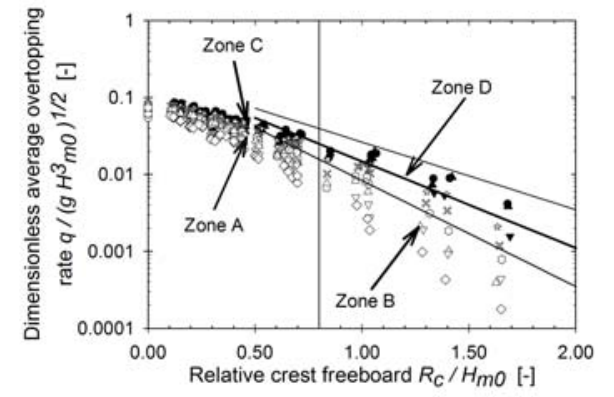

$$
\begin{array}{lll|}
\hline \text { UG10 } \cot \alpha=2.75 & \triangle \quad \text { UG10 } \cot \alpha=0.84 \\
\text { UG10 } \cot \alpha=2.14 & \quad \text { UG10 } \cot \alpha=0.58 \\
\text { UG10 } \cot \alpha=1.73 & \quad \text { UG10 } \cot \alpha=0.36 \\
\text { UG10 } \cot \alpha=1.43 \quad \text { Eq.(1) } \\
* \quad \text { UG10 } \cot \alpha=1.19 & \text { Eq.(1)_99\% } \\
\text { UG10 } \cot \alpha=1.00 & \text { Smid et al. (2001), } \cot \alpha=1.5 \\
\hline
\end{array}
$$

Figure 8. Graph of dimensionless average overtopping rate $q / \sqrt{g H_{m 0}^{3}}$ as a function of the relative crest freeboard $R_{c} / H_{m 0}$, for all values of $\cot \alpha$ tested during the UG10 test series.

The vertical spreading of the data points, largely caused by differences in slope angle, decreases for decreasing relative crest freeboard $R_{c} / H_{m 0}$. This behaviour corresponds to the decrease in the effect of the slope angle for decreasing relative crest freeboard.

The predicted effect of the relative crest freeboard on the overtopping behaviour for the asymptotic case of a vertical wall ( $\cot \alpha=0.0$ ) is shown in Fig. 9. In particular, predictions by Eq. (2), Eq. (3), Eq. (5) and the DHNN tool are compared with test results of the CLASH database for plain vertical walls with non-impulsive conditions. These test results include the test results for a zero crest freeboard by Smid et al. (2001).

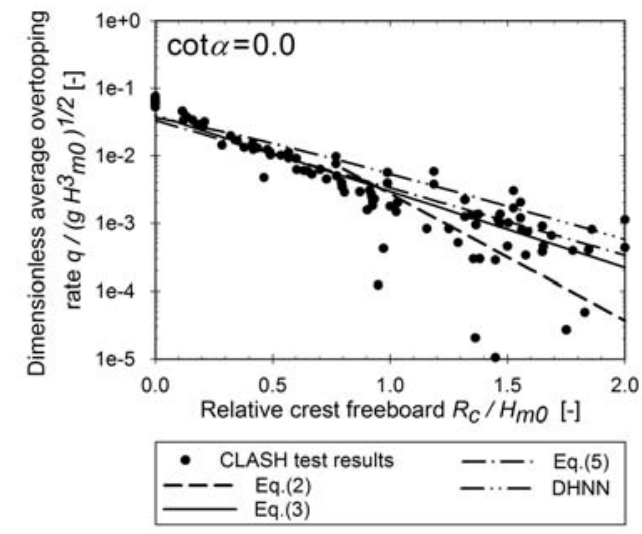

Figure 9. Graph of dimensionless average overtopping rate $q / \sqrt{g H_{m 0}^{3}}$ as a function of the relative crest freeboard $R_{c} / H_{m 0}$, for $\cot \alpha=\mathbf{0 . 0}$.

Based on the CLASH test results, two zones are identified: a zone with relatively little scatter for smaller relative crest freeboards, and a zone with larger scatter for larger relative crest freeboards. The transition between both zones occurs approximately at $R_{c} / H_{m 0}=0.8$.

The differences between the prediction lines of Eq. (3), Eq. (5) and the DHNN tool are relatively small. All three prediction lines approximately correspond to a straight line for $0.0 \leq R_{c} / H_{m 0} \leq 2.0$,

suggesting that the effect of the relative crest freeboard on the average overtopping rate of vertical walls is described by a single straight line. The data points of the CLASH database are rather closely aligned with these prediction lines for the zone with smaller relative crest freeboards. However, larger scatter occurs in the zone of larger relative crest freeboards, resulting in inconsistencies in the 
predictions. The average overtopping rate predicted by Eq. (2), which is only valid in this zone of larger scatter, is smaller than that predicted by Eq. (3), Eq. (5) and the DHNN tool.

Furthermore, the predicted average overtopping rate of Eq. (5) and the DHNN tool for a zero crest freeboard and the extension of Eq. (3) for $R_{c} / H_{m 0}=0.0$ (dotted line) is positioned below the test results by Smid et al. (2001). It is clear that the latter test results have not been used in the derivation of those empirical prediction formulae.

\section{EFFECT OF WAVE STEEPNESS ON OVERTOPPING RATE OF STEEP LOW-CRESTED STRUCTURES}

The effect of the wave steepness combines the effects of the wave height $H_{m 0}$ and the wave period $T_{m-1,0}$. The wave height $H_{m 0}$ is part of the denominators of the dimensionless average overtopping rate $q / \sqrt{g H_{m 0}^{3}}$ and of the dimensionless crest freeboard $R_{c} / H_{m 0}$ in the empirical prediction formulae in Eq. (1), Eq. (2), Eq. (3), Eq. (5) and Eq. (6). Accordingly, for specific values of the wave period $T_{m-1,0}$, crest freeboard $R_{c}$ and slope angle $\cot \alpha$, an increase in wave height results in an increase in average overtopping rate $q$.

On the other hand, the wave period is not part of those formulae, which means that most of the considered prediction methods assume that the effect of the wave period on the overtopping behaviour at steep slopes with non-breaking waves and at vertical walls with non-impacting waves is negligible.

The independent effect of the wave period on the average overtopping rate of steep low-crested structures is studied based on the UG10 test results. The dimensionless average overtopping rate $q / \sqrt{g H_{m 0}^{3}}$ (logarithmic scale) for test results of the UG10 dataset with $R_{c}=0.07 \mathrm{~m}$ and $\cot \alpha=1.73$ is plotted versus the wave steepness $s_{m-1,0}$ (linear scale) in Fig. 10. The corresponding data points are categorized according to the wave height $H_{m 0}$, which varies from $0.067 \mathrm{~m}, 0.10 \mathrm{~m}$ to $0.133 \mathrm{~m}$. Values of $q / \sqrt{g H_{m 0}^{3}}$ predicted by Eq. (1) and by the DHNN tool for $H_{m 0}=0.067 \mathrm{~m}$ are added to Fig. 10, with their $90 \%$ prediction intervals. The value of the relative crest freeboard $R_{c} / H_{m 0}$ corresponding to $H_{m 0}=0.067$ m equals 1.04 .

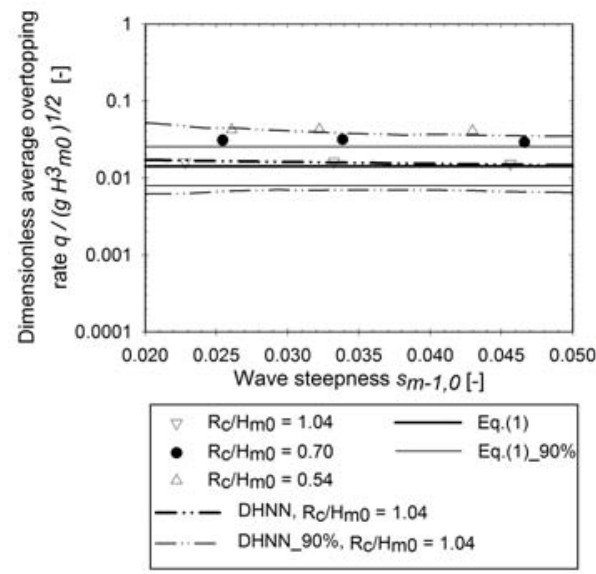

Figure 10. Graph of dimensionless average overtopping rate $q / \sqrt{g H_{m 0}^{3}}$ as a function of the wave steepness $s_{m-1,0}$. Independent effect of the wave period.

The differences in the dimensionless average overtopping rate $q / \sqrt{g H_{m 0}^{3}}$ between the data points in Fig. 10 are mainly due to variations in wave height and accordingly in relative crest freeboard. Only very small differences occur between the data points for a particular wave height. The data points corresponding to $H_{m 0}=0.067 \mathrm{~m}$ are closely aligned with the horizontal prediction line of Eq. (1) and with the prediction line of the DHNN tool. Correspondingly, the independent effect of the wave period is negligible compared to the effect of the relative crest freeboard for the example in Fig. 10. Similar 
graphs, generated for different values of crest freeboard and slope angle, confirm this limited dependency on the wave period.

Furthermore, a comparison between the vertical spreading of the data points of the UG10 dataset between Fig. 3 to Fig. 5 on one hand and Fig. 10 (for a specific value of $H_{m 0}$ ) on the other hand, shows that the effect of the wave period is also negligible compared to the effect of the slope angle.

In conclusion, the effect of the wave period on the average overtopping rate of steep low-crested structures appears to be limited compared to the effects of the relative crest freeboards and the slope angle, and is therefore neglected in the present paper.

\section{NEW SET OF PREDICTION FORMULAE FOR STEEP LOW-CRESTED STRUCTURES BASED ON THE UG10 DATASET}

As illustrated above, the considered prediction models from literature are not able to predict the effects of the slope angle and small relative crest freeboards sufficiently accurate for steep low-crested structures, in particular for the steeper slopes. Therefore, a set of new prediction formulae is derived, based on the UG10 test results, which is able to more accurately predict the average overtopping rate for steep low-crested structures. Furthermore, the asymptotic overtopping behaviour for vertical walls and structures with zero crest freeboards is incorporated in this set of formulae, based on test results available in literature for those structures. The methodology applied to achieve the set of new formulae is explained below.

\section{Methodology for derivation of the set of new prediction formulae}

Since the effect of the wave period on the average overtopping rate of steep low-crested structures is neglected, the rate only depends on the slope angle $\cot \alpha$ and the relative crest freeboard $R_{c} / H_{m 0}$, as expressed in Eq. (10) ( $f$ represents a random function here):

$$
\frac{q}{\sqrt{g H_{m 0}^{3}}}=f\left(\cot \alpha, \frac{R_{c}}{H_{m 0}}\right)
$$

The identification of the expression for the function $f$ is based on the log-linear graph of $q / \sqrt{g H_{m 0}^{3}}$ versus $R_{c} / H_{m 0}$ given in Fig. 8. For a particular value of $\cot \alpha$, a double-exponential relationship exists between $q / \sqrt{g H_{m 0}^{3}}$ and $R_{c} / H_{m 0}$. The typical expression for the exponential relationship between $q / \sqrt{g H_{m 0}^{3}}$ and $R_{c} / H_{m 0}$ used in literature (EurOtop 2007; Owen 1980) is:

$$
\frac{q}{\sqrt{g H_{m 0}^{3}}}=a \exp \left(b \frac{R_{c}}{H_{m 0}}\right)
$$

The transition point between both exponential relationships is positioned at $R_{c} / H_{m 0}=0.80$ (Fig. 8). Additionally, the effect of the slope angle is negligible for $\cot \alpha>1.5$ (see Fig. 3 and Fig. 5). As a result, four zones with specific expressions for the exponential relationship between $q / \sqrt{g H_{m 0}^{3}}$ and $R_{c} / H_{m 0}$ are defined (Fig. 8). Zones A and B correspond to steeper slopes $(\cot \alpha<1.5)$ with a significant effect of the slope angle on the average overtopping rate. Zones $\mathrm{C}$ and $\mathrm{D}$ cover milder slopes $(\cot \alpha>1.5)$ for which no significant effect of the slope angle is observed. Accordingly, the coefficients $a$ and $b$ in Eq. (11) are functions of $\cot \alpha$ for zones A and B, while these coefficients are empirical constants for zones $\mathrm{C}$ and $\mathrm{D}$.

The effect of a small relative crest freeboard is taken into account in zones A and C. Zones B and $\mathrm{D}$ correspond to larger relative crest freeboards. A summary of the ranges of application of $\cot \alpha$ and

\begin{tabular}{|c|c|c|}
\hline & $\cot \alpha<1.5$ & $\cot \alpha>1.5$ \\
\hline$R_{c} / H_{m 0} \leq 0.8$ & Zone A & Zone C \\
\hline$R_{c} / H_{m 0} \geq 0.8$ & Zone B & Zone D \\
\hline
\end{tabular}
$R_{c} / H_{m 0}$ is given in Table 5 . 
Note that the expressions for the exponential relationships for zone A (zone C) and zone B (zone D) are forced to give an identical dimensionless average overtopping rate for $R_{c} / H_{m 0}=0.8$.

The expressions for the coefficients $a$ and $b$ in zone $\mathrm{A}$ and zone $\mathrm{B}$ as a function of the slope angle are derived as follows. Taking the logarithm of both sides of Eq. (11) yields Eq. (12) (the coefficients $a$ and $b$ have either the index A or B).

$$
\begin{gathered}
\ln \left(\frac{q}{\sqrt{g H_{m 0}^{3}}}\right)=a^{\prime}+b \frac{R_{c}}{H_{m 0}} \\
a=\exp \left(a^{\prime}\right)
\end{gathered}
$$

Sets of values of the coefficients $a^{\prime}$ and $b$ in Eq. (12a) are determined using a linear regression analysis applied to each subset of the UG10 dataset with identical values of the slope angle, separately for zone A and zone B. The corresponding values of the coefficient $a$ are obtained using Eq. (12b).

The sets of values of the coefficients $a_{A}$ and $b_{A}$ for zone A (Table 6) have been calculated applying this methodology. The values of $a_{A}$ and $b_{A}$ for $\cot \alpha=0.0$, provided in Table 6 , have been established applying a different reasoning. The coefficient $a_{A}=0.062$ corresponds to the dimensionless average overtopping rate predicted by Smid et al. (2001) for vertical walls with a zero crest freeboard: $q / \sqrt{g H_{m 0}^{3}}=0.062$. The coefficient $b_{A}$ for $\cot \alpha=0.0$ is determined using linear regression analysis based on Eq. (12) and taking into account the coefficient $a_{A}=0.062$, for the subset of the CLASH database for plain vertical walls with non-impulsive wave attack and with $R_{c} / H_{m 0} \leq$

\begin{tabular}{|c|c|c|}
\hline \multicolumn{3}{|c|}{$\begin{array}{l}\text { Table } 6 \text {. Coefficients } a_{A} \text { and } \\
b_{A} \text { as a function of the slope } \\
\text { angle for zone } A \text {. }\end{array}$} \\
\hline $\cot \alpha[-]$ & $a_{A}$ & $b_{A}$ \\
\hline 1.43 & 0.104 & -1.920 \\
\hline 1.19 & 0.099 & -2.140 \\
\hline 1.00 & 0.094 & -2.386 \\
\hline 0.84 & 0.096 & -2.627 \\
\hline 0.58 & 0.082 & -2.713 \\
\hline 0.36 & 0.082 & -3.066 \\
\hline 0.00 & 0.062 & -3.451 \\
\hline
\end{tabular}
0.8. This subset includes the test results for a zero crest freeboard by Smid et al. (2001).

The sets of values of the coefficients $a_{B}$ and $b_{B}$ for zone B (Table 7) are achieved in a similar way compared to the coefficients $a_{A}$ and $b_{A}$. Since the prediction formulae for zone A and zone B are assumed to give an identical value of $q / \sqrt{g H_{m 0}^{3}}$ for $R_{c} / H_{m 0}=0.8$, the following relationship between $a_{B}^{\prime}$ and $b_{B}$ has been applied when determining the values of the coefficients $a_{B}$ and $b_{B}$ in Table 7 :

$$
a_{B}^{\prime}=\ln \left(\left(\frac{q}{\sqrt{g H_{m 0}^{3}}}\right)_{0.8, A}\right)-b_{B} 0.8
$$

\begin{tabular}{|c|c|c|}
\hline $\cot \alpha[-]$ & $a_{B}$ & $b_{B}$ \\
\hline 1.43 & 0.197 & -2.643 \\
\hline 1.19 & 0.189 & -2.948 \\
\hline 1.00 & 0.181 & -3.176 \\
\hline 0.84 & 0.259 & -3.868 \\
\hline 0.58 & 0.159 & -3.661 \\
\hline 0.36 & 0.217 & -4.409 \\
\hline
\end{tabular}


Values of the coefficients $a_{B}$ and $b_{B}$ for $\cot \alpha=0.0$ are not given in Table 7 (for zone B), since the relationship between $q / \sqrt{g H_{m 0}^{3}}$ and $R_{c} / H_{m 0}$ is unclear for the test results of the CLASH database for plain vertical walls with non-impulsive conditions and with $R_{c} / H_{m 0} \geq 0.8$, due to the rather large scatter.

The values of the coefficient $a_{B}$ in Table 7 are positioned around the value 0.2 for all slope angles in the UG10 test series. Therefore, the coefficient $a_{B}$ is assumed to be a constant: $a_{B}=0.2$. The corresponding values of the coefficient $b_{B}$, referred to as $b_{B_{-} 0.2}$, are determined by expressing (1) that the dimensionless average overtopping rate at $R_{c} / H_{m 0}=0.0$ takes the value of $a_{B}=0.2$, $\left(q / \sqrt{g H_{m 0}^{3}}\right)_{0.0}=0.2$, and (2) that the prediction formulae for zone A and zone B are assumed to give an identical value of $q / \sqrt{g H_{m 0}^{3}}$ for $R_{c} / H_{m 0}=0.8,\left(q / \sqrt{g H_{m 0}^{3}}\right)_{0.8, A}=\left(q / \sqrt{g H_{m 0}^{3}}\right)_{0.8, B}$. In correspondence with Eq. (2), the value of the coefficient $a_{B}$ for $\cot \alpha=0.0$ is also assumed to be 0.2 . Accordingly, this methodology is also applied to determine the value of the coefficient $b_{B_{-} 0.2}$ for $\cot \alpha=0.0$. The corresponding values of $b_{B_{-} 0.2}$ are given in Table 8 .

\begin{tabular}{|ccc|}
\hline \multicolumn{3}{|l|}{$\begin{array}{l}\text { Table 8. Coefficients } \boldsymbol{a}_{B} \text { and } b_{B} \mathbf{0 . 2} \\
\text { as a function of the slope angle } \\
\text { for zone } B \text {, assuming } a_{B}=\mathbf{0 . 2} \text {. }\end{array}$} \\
\hline cot $\alpha[-]$ & $a_{B}$ & $b_{B} 0.2$ \\
\hline 1.43 & 0.200 & -2.662 \\
1.19 & 0.200 & -3.015 \\
1.00 & 0.200 & -3.301 \\
0.84 & 0.200 & -3.545 \\
0.58 & 0.200 & -3.951 \\
0.36 & 0.200 & -4.306 \\
0.00 & 0.200 & -4.914 \\
\hline
\end{tabular}

Eventually, the expressions for the coefficients $a$ and $b$ as a function of the slope angle for zones $\mathrm{A}$ and B are achieved by fitting a curve through the values of $a$ and $b$ for the different slope angles. Note that a similar approach has been used by Goda (2009) for deriving Eq. (5b) and Eq. (5c) based on test results of the CLASH database for smooth impermeable slopes with $0.0 \leq \cot \alpha \leq 7.0$. Accordingly, values of the coefficients $a$ and $b$, applicable both in zone A and zone B, can be determined based on the values of the coefficients $A_{0}$ and $B_{0}$ calculated by Eq. (5b) and Eq. (5c) respectively.

The values of the coefficients $a_{A}$ and $a_{B}$ from Table 7 and Table 8 are shown as a function of $\cot \alpha$ in Fig. 11 (marked using white symbols). The values of the coefficients $a$ derived based on Eq. (5b) are also added (black dots). Furthermore, for $\cot \alpha=0.0$ the coefficients $a$ corresponding to Eq. (2) ( $a_{B}=0.2$ ) and Eq. (3) ( $a=0.04$, valid for zones A and B) are given, marked on the vertical axis using a black square and a black triangle respectively.

A similar graph is shown in Fig. 12 for the coefficient $b$.

Rather large differences occur between the values of $a$ and $b$ from Table 7 and Table 8 on the one hand, and their predictions by Eq. (5b) and Eq. (5c) on the other hand. These differences are presumably caused by combined effect of three aspects which play an important role in the derivation of Eq. (5b) and Eq. (5c). Firstly, these equations have been derived based on test results for inclined slopes and vertical walls with a wide range of wave conditions (breaking, non-breaking, impacting, non-impacting). Furthermore, the assumption has been made that a single exponential relationship exists between $q / \sqrt{g H_{m 0}^{3}}$ and $R_{c} / H_{m 0}$ for a particular value of $\cot \alpha$, over the wide range of relative crest freeboards $0.0 \leq R_{c} / H_{m 0} \leq 5.7$. Finally, it is noted that Goda (2009) achieves a rather poor alignment between the curves corresponding to Eq. (5b) and Eq. (5c) and the experimentally obtained values of $A_{0}$ and $B_{0}$ in the range $0.0<\cot \alpha<2.0$. 


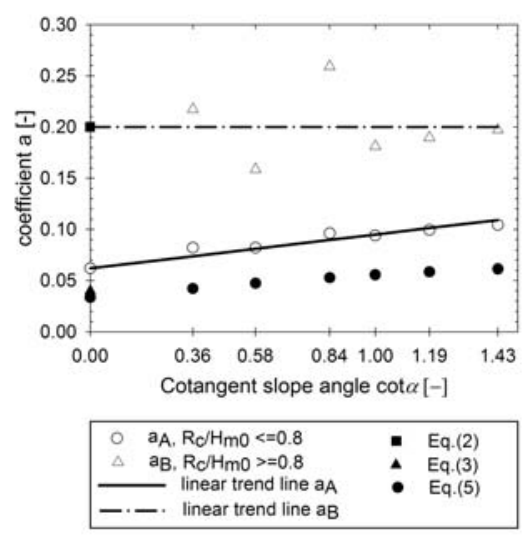

Figure 11. Coefficients $a_{A}$ and $a_{B}$ as a function of the slope angle.

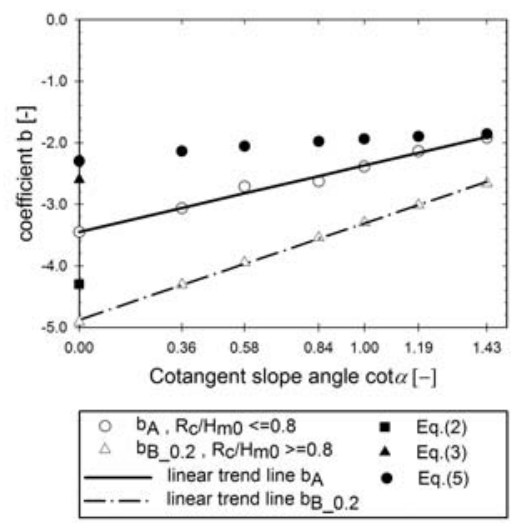

Figure 12. Coefficients $b_{A}$ and $b_{B_{-} 0.2}$ as a function of the slope angle.

As illustrated in Fig. 11 and Fig. 12, the coefficients $a_{A}, b_{A}$ and $b_{B_{-} 0.2}$ approximately follow a linear trend when plotted as a function of the cotangent of the slope angle $\cot \alpha$. Accordingly, these coefficients are expressed as a linear function of $\cot \alpha$. The corresponding expressions are given in the following two sections for zone $\mathrm{A}$ and zone $\mathrm{B}$ respectively.

The exponential relationship between $q / \sqrt{g H_{m 0}^{3}}$ and $R_{c} / H_{m 0}$ for zone $\mathrm{C}$ is discussed afterwards.

Since all UG10 data points are located within the $90 \%$ prediction interval of Eq. (1) in zone D (Fig. 8), a new prediction formula for zone D has not been derived. Hence, the empirical constants $a_{D}$ and $b_{D}$ in zone D are known: $a_{D}=0.2$ and $b_{D}=-2.6$ (Eq. 1).

Note that the intersection between the linear trend line of the coefficient $b_{B_{-} 0.2}$ and the vertical axis, positioned at -4.914 (Fig. 12), is relatively close to the coefficient $b=-4.3$ of Eq. (2). Combining this observation with the constant value of 0.2 for the coefficient $a_{B}$, it appears that the empirical formula of Eq. (2) is a relatively accurate prediction formula for the average overtopping rate at vertical walls with non-impulsive wave attack and with $R_{c} / H_{m 0} \geq 0.8$. This finding is inconsistent with the validity of Eq. (3). The reason for this inconsistency is unclear and therefore subject for further research.

Prediction formula for zone A: $\cot \alpha<\mathbf{1 . 5}$ and $R_{c} / H_{m 0} \leq \mathbf{0 . 8}$

Under the assumption that the coefficients $a_{A}$ and $b_{A}$ are linear functions of $\cot \alpha$, the following prediction formula is derived for the average overtopping rate in zone $\mathrm{A}$ : 


$$
\frac{q}{\sqrt{g H_{m 0}^{3}}}=(0.033 \cot \alpha+0.062) \exp \left((1.08 \cot \alpha-3.45) \frac{R_{c}}{H_{m 0}}\right)
$$

The ranges of application for Eq. (14) are:

$$
\begin{aligned}
& 0.0 \leq \cot \alpha \leq 1.43 \\
& 0.0 \leq \frac{R_{c}}{H_{m 0}} \leq 0.8
\end{aligned}
$$

The reliability of Eq. (14) is expressed by using an overtopping discharge factor, similar to Owen (1980). In a first step, the root-mean-square error rmse is calculated, defined in Eq. (17).

$$
r m s e=\sqrt{\frac{1}{N_{\text {test }}} \sum_{n=1}^{N_{\text {test }}}\left[\log \left(\frac{q_{\text {measured }}}{\sqrt{g H_{m 0}^{3}}}\right)_{n}-\log \left(\frac{q_{\text {predicted }}}{\sqrt{g H_{m 0}^{3}}}\right)_{n}\right.}
$$

$N_{\text {test }}$ is the number of test results in the particular subset of the UG10 dataset (zone A) and $n$ is the index running through the test results. When assuming the logarithms of the measured dimensionless average overtopping rate exhibit a normal probability distribution about the logarithms of the predicted dimensionless average overtopping rate, $90 \%$ of the measured overtopping rates are located within the interval defined by Eq. (18a). The corresponding expressions for the upper and lower boundaries of the $90 \%$ prediction interval of $q_{\text {measured }} / \sqrt{g H_{m 0}^{3}}$ are given in Eq. (18b). The factor $10^{1.645 \mathrm{rmse}}$ is referred to as the overtopping discharge factor.

$$
\begin{gathered}
\log \left(\frac{q_{\text {measured }}}{\sqrt{g H_{m 0}^{3}}}\right)_{90 \%}=\log \left(\frac{q_{\text {predicted }}}{\sqrt{g H_{m 0}^{3}}}\right) \pm 1.645 \text { rmse } \\
\Rightarrow\left\{\begin{array}{l}
\left(\frac{q_{\text {measured }}}{\sqrt{g H_{m 0}^{3}}}\right)_{90 \%, \text { upper }}=\left(\frac{q_{\text {predicted }}}{\sqrt{g H_{m 0}^{3}}}\right) 10^{1.645 \text { rmse }} \\
\left(\frac{q_{\text {measured }}}{\sqrt{g H_{m 0}^{3}}}\right)_{90 \%, \text { lower }}=\left(\frac{q_{\text {predicted }}}{\sqrt{g H_{m 0}^{3}}}\right) / 10^{1.645 \text { rmse }}
\end{array}\right.
\end{gathered}
$$

The value of rmse is 0.06 in zone A for the UG10 dataset and the CLASH database for plain vertical walls with non-impulsive wave attack. The corresponding overtopping discharge factor is 1.25.

Prediction formula for zone B: $\cot \alpha<\mathbf{1 . 5}$ and $R_{c} / H_{m 0} \geq \mathbf{0 . 8}$

The following prediction formula is derived for the average overtopping rate in zone $\mathrm{B}$, based on the results that $a_{B}=0.2$ and $b_{B_{-} 0.2}$ is a linear function of $\cot \alpha$ :

$$
\frac{q}{\sqrt{g H_{m 0}^{3}}}=0.2 \exp \left((1.57 \cot \alpha-4.88) \frac{R_{c}}{H_{m 0}}\right)
$$

The ranges of application for Eq. (19) are given in Eq. (20) and Eq. (21).

$$
\begin{aligned}
& 0.0 \leq \cot \alpha \leq 1.43 \\
& 0.8 \leq \frac{R_{c}}{H_{m 0}} \leq 2.0
\end{aligned}
$$

The value of rmse is 0.10 in zone B for the test results of the UG10 dataset, resulting in an overtopping discharge factor of 1.47. 
Prediction formula for zone C: $\cot \alpha>\mathbf{1 . 5}$ and $R_{c} / H_{m 0} \leq \mathbf{0 . 8}$

Since the effect of the slope angle is assumed to be negligible in zone $\mathrm{C}$, the coefficients $a_{C}$ and $b_{C}$ are empirical constants. A number of restrictions apply to the corresponding values, as discussed below.

The prediction formula for zone $\mathrm{C}$ is assumed to give an identical average overtopping rate for $R_{c} / H_{m 0}=0.80$ as Eq. (1) which is valid in zone D. Additionally, based on the test results of Smid et al. (2001) for structures with $\cot \alpha=1.5$ and a zero crest freeboard, the value of $q / \sqrt{g H_{m 0}^{3}}$ corresponding to $R_{c} / H_{m 0}=0.0$ is expected to be equal to 0.062 . However, this disagrees with the linear trend followed by the coefficients $a_{A}$ in Fig. 11: applying Eq. (14) for $\cot \alpha=1.5$, a value of $q / \sqrt{g H_{m 0}^{3}}=$ 0.11 is found. Consequently, the hypothesis of a constant average overtopping rate for steep slopes with a zero crest freeboard (Smid et al. 2001) is rejected.

The coefficient $a_{C}$ is given the value 0.11 , while the restriction for the predicted dimensionless average overtopping rate at $R_{c} / H_{m 0}=0.8$ determines the coefficient $b_{C}$. The corresponding prediction formula for zone $\mathrm{C}$ is given in Eq. (22). Note that the value of $b_{C}$ is approximately equal to the calculated value of $b_{A}$ for $\cot \alpha=1.5$.

The ranges of application for Eq. (22) are given in Eq. (23) and Eq. (24).

$$
\begin{gathered}
\frac{q}{\sqrt{g H_{m 0}^{3}}}=0.11 \exp \left(-1.85 \frac{R_{c}}{H_{m 0}}\right) \\
1.73 \leq \cot \alpha \leq 2.75 \\
0.0 \leq \frac{R_{c}}{H_{m 0}} \leq 0.8
\end{gathered}
$$

The corresponding value of rmse is 0.04 in zone $\mathrm{C}$ for the test results of the UG10 dataset, resulting in an overtopping discharge factor of 1.18 .

\section{Important remark on new set of prediction formulae}

The transition point for $\cot \alpha$ between zone A (zone B) and zone C (zone D) has been set to 1.50. However, no results in the UG10 dataset are available for the exact value of $\cot \alpha=1.50$. As a consequence, Eq. (14) and Eq. (19) are only valid up to $\cot \alpha=1.43$, while Eq. (22) is only valid for values of $\cot \alpha$ larger than 1.73. In the range $1.43<\cot \alpha<1.73$, the minimum of both values of $q / \sqrt{g H_{m 0}^{3}}$ determined by the expressions for $\cot \alpha<1.50$ and $\cot \alpha>1.50$ should be taken.

\section{Graphical output of new set of prediction formulae}

An overview of the UG10 formulae with their ranges of application for $\cot \alpha$ and $R_{c} / H_{m 0}$ is given

\begin{tabular}{|c|c|c|c|}
\hline & $0.0 \leq \cot \alpha \leq 1.43$ & $1.43<\cot \alpha<1.73$ & $1.73 \leq \cot \alpha \leq 2.75$ \\
\hline $0.0 \leq R_{c} / H_{m 0} \leq 0.8$ & Eq. (19) & $\min ($ Eq. (19), Eq. (22)) & Eq. (22) \\
\hline $0.8 \leq R_{c} / H_{m 0} \leq 2.0$ & Eq. (14) & $\min ($ Eq. (1), Eq. (14)) & Eq. (1) \\
\hline
\end{tabular}
in Table 9. The corresponding set of new prediction formulae is referred to as the UG10 formulae. Note that for $\cot \alpha>1.5$ and $R_{c} / H_{m 0} \geq 0.8$, Eq. (1) is still valid as indicated in Table 9.

The three figures below illustrate the validity of the UG10 formulae: Fig. 13, for the effect of the slope angle, and Fig. 14 and Fig. 15 for the effect of the relative crest freeboard.

The graph in Fig. 13 is identical to Fig. 4b, except that the prediction line corresponding to Eq. (6) is replaced by the prediction line of the UG10 formulae from Table 9 for $R_{c} / H_{m 0}=0.45$. The $90 \%$ 
prediction interval of the UG10 formulae is also added. As expected, the data points approach the UG10 formulae well. It is noted that the average predictions by the DHNN tool are also quite accurate. However, this conclusion is not generally valid. The predicted effect of the slope angle by the DHNN tool is less accurate for larger relative crest freeboards as shown above.

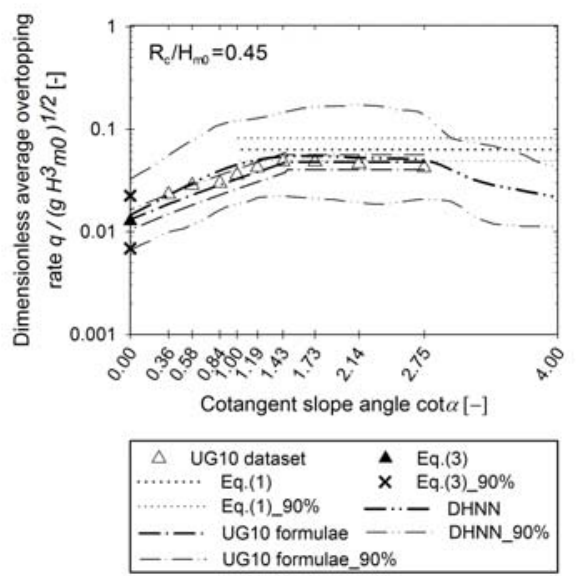

Figure 13. Predictions of dimensionless average overtopping rate $q / \sqrt{g H_{m 0}^{3}}$ by the UG10 formulae as a function of the slope angle $\cot \alpha$, for $R_{c} / H_{m 0}=\mathbf{0 . 4 5}$.

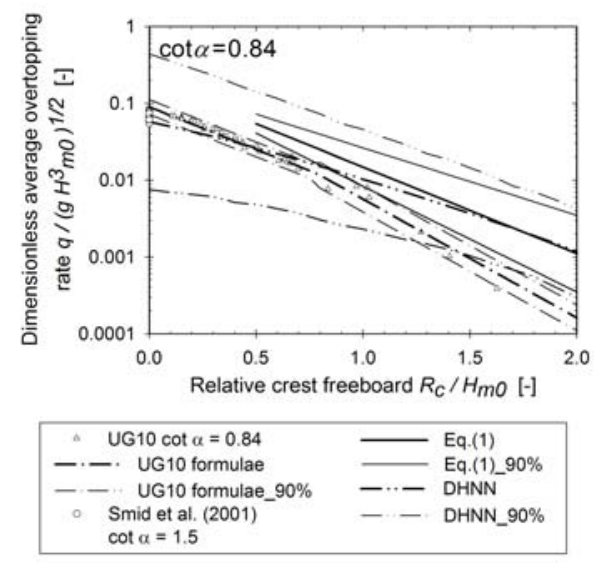

Figure 14. Predictions of dimensionless average overtopping rate $q / \sqrt{g H_{m 0}^{3}}$ function of the relative crest freeboard $R_{c} / H_{m 0}$, for $\cot \alpha=\mathbf{0 . 8 4}$.

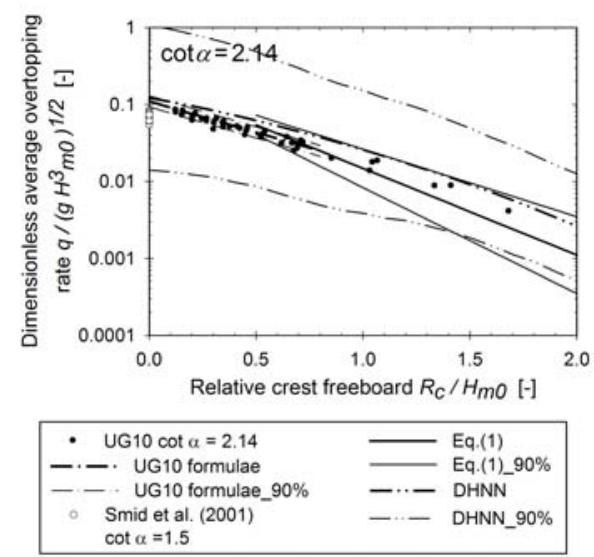

Figure 15. Predictions of dimensionless average overtopping rate $q / \sqrt{g H_{m 0}^{3}}$ by the UG10 formulae as a function of the relative crest freeboard $R_{c} / H_{m 0}$, for $\cot \alpha=\mathbf{2 . 1 4}$. 
The effect of the relative crest freeboard on the dimensionless average overtopping rate is shown in a log-linear graph in both Fig. 14 and Fig. 15 for test results of the UG10 dataset with $\cot \alpha=0.84$ and $\cot \alpha=2.14$ respectively. The prediction lines corresponding to the UG10 formulae (Table 9) are also given in Fig. 14 and Fig. 15. Furthermore, predictions by the DHNN tool and by Eq. (1), within its range of application for $R_{c} / H_{m 0}$, are added to these figures for comparison. The $90 \%$ prediction intervals of all prediction methods are also shown. Again, a good agreement exists between the data points of the UG10 dataset and the UG10 formulae. Furthermore, the predictions by these formulae are more accurate compared to the DHNN tool and to Eq. (1), except for zone D in which the UG10 formulae coincide with Eq. (1).

\section{CONCLUSIONS}

The overtopping behaviour of smooth impermeable steep sloping structures with low crest freeboards subjected to non-breaking waves has been analyzed. New experiments have been carried out which enable to study the independent effects of the slope angle $\alpha$, crest freeboard $R_{c}$ and wave steepness $s_{m-1,0}$ on the average overtopping rate of steep low-crested structures. The test results have been compared to the average overtopping rate determined by prediction methods available in literature.

Based on this comparison, it is clear that the average overtopping rate of steep low-crested structures is not only determined by the crest freeboard and wave height, but also by the slope angle. The effect of the slope angle is rather small for slopes with $\cot \alpha>1.5$. However, for $\cot \alpha<1.5 \mathrm{a}$ significant decrease in average overtopping rate occurs towards the rate for vertical walls with nonimpacting wave attack. Furthermore, the effect of the relative crest freeboard on the average overtopping rate of steep low-crested structures subjected to non-breaking waves is expressed by a double-linear relationship in a log-linear graph of $q / \sqrt{g H_{m 0}^{3}}$ versus $R_{c} / H_{m 0}$. The transition point between both straight lines has been positioned at $R_{c} / H_{m 0}=0.8$. The straight line with $0.0 \leq R_{c} / H_{m 0} \leq 0.8$ is largely determined by test results for structures with zero crest freeboards. The effect of the wave period is small compared to the other effects.

Existing prediction methods appear unable to predict the significant effects of the slope angle and small relative crest freeboards sufficiently accurate for steep low-crested structures. Therefore, a new set of prediction formulae has been proposed, based on the new experimental test results, and based on test results available in literature for vertical walls subjected to non-impacting waves and for structures with zero crest freeboard. The good agreement between the experimental test results and the newly predicted average overtopping rate illustrates the validity of the set of new prediction formulae for steep slopes and small relative crest freeboards.

\section{ACKNOWLEDGEMENTS}

The research is funded by a Ph.D. grant of the Fund for Scientific Research Flanders (FWO Vlaanderen), Belgium. We sincerely thank the technicians at Ghent University, (Belgium) for their help with constructing the test set-up. Jan Goormachtigh and Walid Harchay, are strongly acknowledged for assisting in the experiments leading to the UG10 dataset. Furthermore, we wish to thank Jentsje Van der Meer, Julien De Rouck and the anonymous reviewers for their comments and suggestions on the manuscript.

\section{GLOSSARY}

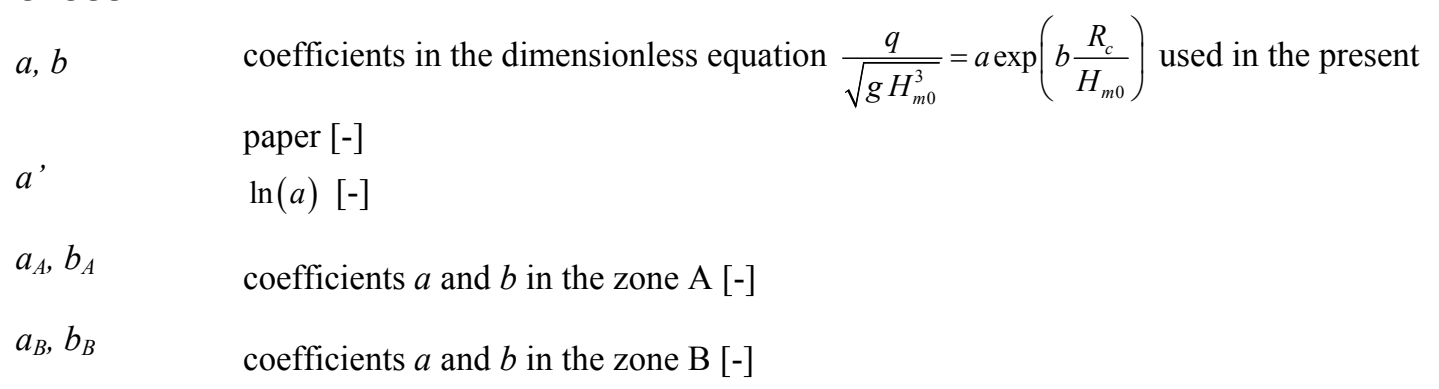




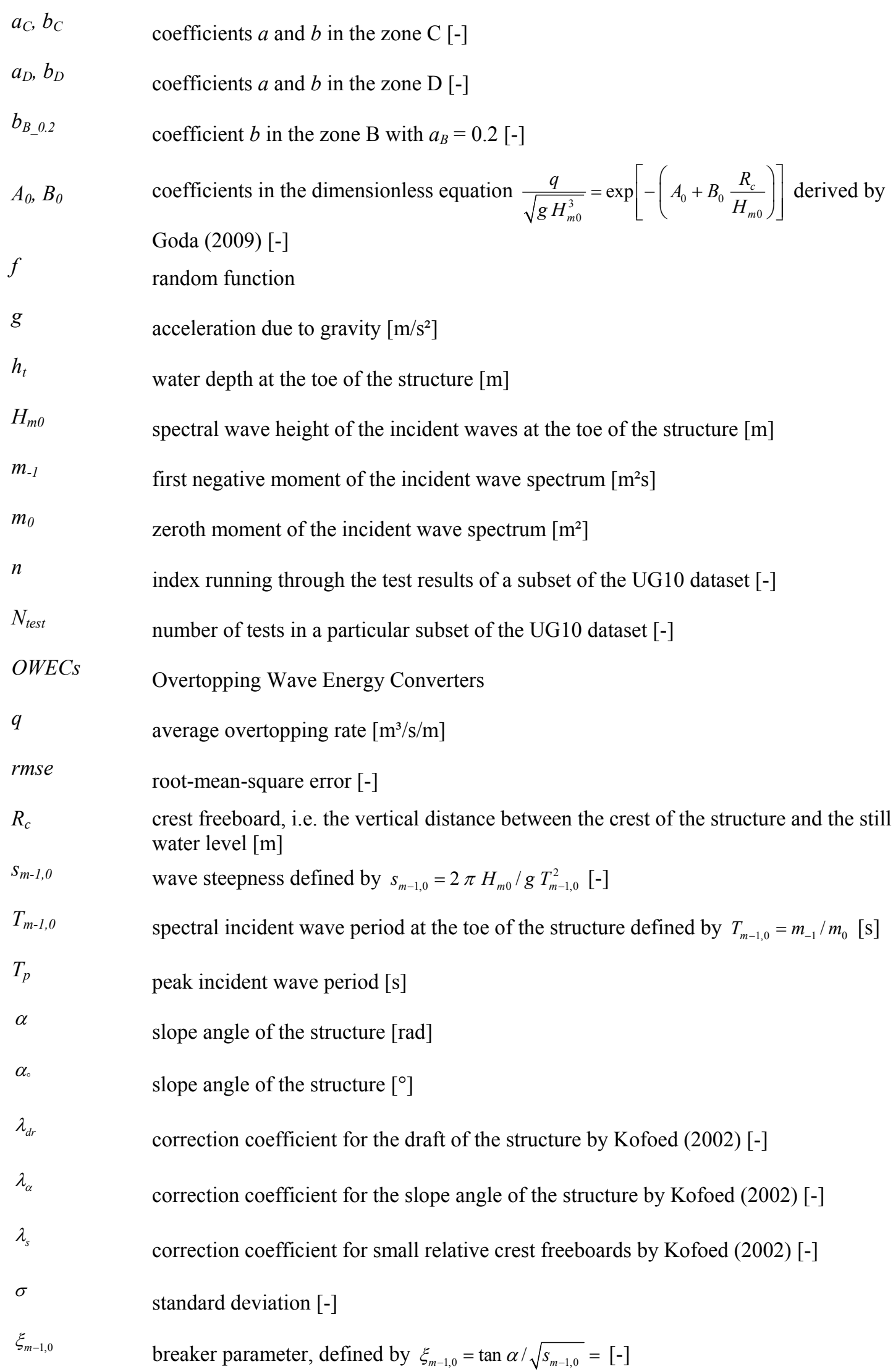




\section{REFERENCES}

Battjes, J.A., 1974. Computation of set-up, longshore currents, run-up and overtopping due to windgenerated waves. Ph.D. Thesis, Technical University Delft, Delft.

Besley, P., 1999. Overtopping of seawalls - design and assessment manual, R\&D Technical Report W178, Environment Agency, Bristol, UK.

De Rouck, J. and Geeraerts, J., 2005. CLASH - final report: full scientific and technical report. http://www.clash-eu.org.

EAK, 2002. Empfehlungen des Arbeitsausschusses Küstenschutzwerke. Die Küste. H. 65.

EurOtop, 2007. 'EurOtop. Wave Overtopping of Sea Defences and Related Structures: Assessment Manual', Environment Agency, UK/ENW Expertise Netwerk Waterkeren, NL/KFKI Kuratorium für Forschung im Küsteningenieurwesen, DE, Pullen, T., Allsop, N.W.H., Bruce, T., Kortenhaus, A., Schüttrumpf, H. and van der Meer, J.W. http://www.overtoppingmanual.com.

Franco, L., de Gerloni, M. and van der Meer, J., 1994. Wave overtopping on vertical and composite breakwaters. In Proc. 24th International Conference on Coastal Engineering, New York, ASCE, pp. 1030-1044.

Goda, Y., 2009. Derivation of unified wave overtopping formulas for seawalls with smooth, impermeable surfaces based on selected CLASH datasets. Coastal Engineering, 56(4): pp. 385-399.

Kofoed, J.P., 2002. Wave overtopping of Marine Structures - Utilization of Wave Energy. PhD Thesis, Aalborg University, Aalborg, DK.

Kofoed, J.P. and Burcharth, H.F., 2002. Estimation of overtopping rates on slopes in wave power devices and other low crested structures., 28th International Conference on Coastal Engineering (ICCE 2002), Cardiff, Wales.

Mansard, E.P.D. and Funke, E.R., 1980. The measurement of incident and reflected spectra using a least squares method. . In Proc. National Conference Publication - Institution of Engineers, Australia, ASCE, n.80/1, pp. 95-96.

Margheritini, L., Vicinanza, D. and Frigaard, P., 2009. SSG wave energy converter: Design, reliability and hydraulic performance of an innovative overtopping device. Renewable Energy, 34(5): pp. 1371-1380.

Owen, M.W., 1980. Design of sea walls allowing for wave overtopping. Report EX 924, Hydraulics Research, Wallingford, UK (1980).

Schüttrumpf, H., 2001. Wellenüberlaufströmung bei Seedeichen - Experimentelle und theoretische Untersuchungen. Phd Thesis, Technischen Universität Carolo-Wilhelmina, Braunschweig, DE.

Smid, R., Schüttrumpf, H. and Möller, J., 2001. Untersuchungen zur Ermittlung der mittleren Wellenüberlaufrate an einer senkrechten Wand und einer 1:1,5 geneigten Böschung für Versuche mit und ohne Freibord (Report on small scale tests, in German), Leichtwei $\beta$ Institute for Hydraulics, Technical University of Braunschweig, Germany.

TAW, 2002. Technical Report Wave Run-up and Wave Overtopping at Dikes, Technische Adviescommissie voor de Waterkeringen, Delft.

van der Meer, J.W., Verhaeghe, H. and Steendam, G.J., 2005. Database on wave overtopping at coastal structures, CLASH WP2 database, Infram, Marknesse, NL.

van Gent, M.R.A., Van den Boogaard, H.F.P., Pozueta, B. and Medina, J.R., 2007. Neural network modelling of wave overtopping at coastal structures. Coastal Engineering, 54(8): pp. 586-593.

Victor, L. and Troch, P., 2010. Development of a test set-up to measure large wave-by-wave overtopping masses. In Proc. Third International Conference on the Application of Physical Modelling to Port and Coastal Protection (Coastlab 10), Barcelona, Spain. 